\title{
Quality of Life Associated Factors in a North African Sample of Lower Limbs Amputees
}

\author{
Houda Migaou, MD, Amine Kalai, MD, Yafa Haj Hassine, MD, Anis Jellad, MD, \\ Soumaya Boudokhane, MD, Zohra Ben Salah Frih, MD \\ Department of Physical Medicine and Rehabilitation, \\ University Hospital of Monastir and Faculty of Medicine of Monastir, Monastir, Tunisia
}

\begin{abstract}
Objective To study factors associated to the quality of life in a North African sample of lower limbs amputees.
Methods We conducted a prospective study in the Department Physical Medicine and Rehabilitation, University Hospital of Monastit, Tunisia. A consecutive sample of patients with amputations of the lower limbs was included. The evaluated parameters were quality of life using the Short-Form quality-of-life questionnaire (SF-36), pain using a visual analog scale, function using, the perimeter of walking (PW), the Special Interest Group of the Amputee Medicine (SIGAM) and the Locomotion Capacities Index of the Prosthetic Profile of the Amputee (LCI), and psychological status thanks to the Hospital Anxiety and Depression scale. In the study, the patients were evaluated at the first consultation (T0) and again at 12 months (T1).

Results We included 85 patients (age, $59.3 \pm 16.7$ years) with a sex ratio of 3 . The patient quality of life was positively correlated to distal type of amputation, traumatic origin, better LCI ( $\mathrm{p} \leq 0.001, \mathrm{r}=0.349)$, SIGAM ( $\mathrm{p}=0.046)$ and PW. A negative correlation was noted with age $(\mathrm{p}=0.012, \mathrm{r}=-0.483)$ and higher psychological scores $(\mathrm{p}=0.002, \mathrm{r}=-0.321)$. Conclusion In our sample of North African lower limbs amputees the age and the functional status were the most important predictors of the quality of life.
\end{abstract}

Keywords Lower limb, Amputation, Quality of life, Prosthesis, Disability

\section{INTRODUCTION}

Lower limb amputation is a surgical procedure in which the removal of a part of the different structures constituting the limb is performed [1]. It leads to a permanent disability affecting the quality of life (QOL), the functional capacities and the psychological status of patients [2-4].
It is noted that the QOL impairment after an amputation is being increasingly recognized as an important factor to consider in rehabilitation programs [5,6]. Many factors associated to QOL in these patients have been reported in the literature, including the use of prosthesis $[7,8]$, the amputation level, phantom limb pain [9] and the employment status [10] of patients who have had an ampu-

Received August 7, 2018; Accepted January 17, 2019

Corresponding author: Anis Jellad

Physical Medicine and Rehabilitation Department, University Hospital of Monastir, Farhat Hached Street, 5000 Monastir, Tunisia. Tel: +216-98-210626, Fax: +216-73-460-478, E-mail: anisjellad@gmail.com

ORCID: Houda Migaou (http://orcid.org/0000-0002-3283-2421); Amine Kalai (http://orcid.org/0000-0003-2964-892X); Yafa Haj Hassine (http://orcid. org/0000-0002-9020-452X); Anis Jellad (http://orcid.org/0000-0002-1848-2103); Soumaya Boudokhane (http://orcid.org/0000-0002-0734-7897); Zohra Ben Salah Frih (http://orcid.org/0000-0003-4896-7897).

(c) This is an open-access article distributed under the terms of the Creative Commons Attribution Non-Commercial License (http://creativecommons.org/ licenses/by-nc/4.0) which permits unrestricted noncommercial use, distribution, and reproduction in any medium, provided the original work is properly cited. Copyright (C) 2019 by Korean Academy of Rehabilitation Medicine 
tation.

It is noted that information on North African data on QOL in lower limb amputees is scarce. Therefore, we carried this study to appreciate the QOL of amputees of the lower limb and evaluate its associated factors in a Tunisian sample.

\section{MATERIALS AND METHODS}

\section{Study design}

This was a prospective study conducted over a period of 3 years from January 2014 to January 2017. The study included patients who were those with an amputation of one or both lower limbs regardless of the etiology and the amputation level. We did not include patients with associated upper limb amputation, and aged under 18 years old.

All patients were informed of the study parameters and gave their consent to participate in the study.

\section{Outcome measures}

\section{Epidemiologic data}

Epidemiologic data were age, gender, medical history, occupation, educational level and socioeconomic level.

\section{Clinical data}

The clinical data regarding the amputation (indication, level) were collected and reviewed. We evaluated the patient's QOL using the Short Form 36 quality-of-life score (SF-36) [11]. Likewise, pain was evaluated using the visual analogue scale (VAS). A functional evaluation was performed regarding the perimeter of walking (PW) which was the distance that the patient was able to walk with the use of canes without stopping, as well as two functional evaluation scores, the Prosthetic Profile of the Amputee of the Special Interest Group of the Amputee Medicine (SIGAM) which is a score comprising six clinical grades (from A to F) concerning the mobility of amputees using prosthesis. In this case, the patients will answer a questionnaire and according to a pre-established algorithm, we will review the clinical grade and the results will be determined. This score has high sensibility, validity and reproducibility [12], and the Locomotion Capacities Index of the Prosthetic Profile of the Amputee (LCI) which consists of 14 questions which are specifically designed to measure the walking ability of lower limb amputees. It was developed in Canada as part of the Prosthetic Profile questionnaire for the Amputee, 'PPA'. This scale has good reliability and is mostly validated in adults [12]. The psychological evaluation of patients was performed using the Hospital Anxiety and Depression Scale (HAD) [13].

\section{Patient assessment rate}

All patients were evaluated at their first consultation (T0) and again at 12 months after (T1).

\section{Statistical analysis}

In this study, the data was processed using the SPSS software version 17.0 (SPSS Inc., Chicago, IL, USA). The quantitative variables were expressed as mean and standard deviation. Also, the qualitative variables were expressed in frequency and percentage. For the comparison of qualitative variables, we used the chi-square test. For the quantitative variables, we used the Fisher test and the ANOVA test. To study the correlation between quantitative variables we used a Pearson test. The difference between the two observed frequencies was considered significant if $\mathrm{p}<0.05$.

\section{RESULTS}

In this study, we included 85 patients with a mean age of $59.3 \pm 16.7$ years. The majority of our patients were men, with a sex ratio of 3.04. Additionally, most of our patients were classified as manual workers. We noted that $53.5 \%$ of our patients were diabetic, $11.9 \%$ had arterial disease, $10.9 \%$ had high blood pressure, and $9.4 \%$ were without a medical history. Vascular etiology of the amputation was the most frequent case, followed by infectious causes and post-traumatic amputation. The most common type of amputation in our series was a transtibial amputation, followed by transfemoral amputations (Table 1).

The initial pain VAS was on average $21.3 \pm 23.2$ at rest and $31.4 \pm 31.1$ at mobilization. The mean LCI for all patients was 28.1 \pm 11.2 . Evaluation of the SIGAM score for all patients showed that the highest clinical rank was stage B. The physical component of the SF-36 QOL score (PCS) was initially more affected than the mental component (MCS) with respectively $32.5 \pm 8.99$ and 36.8 \pm 11.9 . The anxiety component of the HAD (HAD-A) was greater or equal to 11 in $46.6 \%$ of cases. The average PW was 18.6 $\pm 19.3 \mathrm{~m}$ (Table 2). 
Table 1. Demographic and clinical characteristics of the study population

\begin{tabular}{|c|c|c|c|}
\hline \multirow{2}{*}{ Variable } & \multicolumn{3}{|c|}{ Causes of amputation } \\
\hline & Vascular $(n=33)$ & Infection $(n=31)$ & Traumatic $(n=21)$ \\
\hline Age (yr) & $66.48 \pm 9.80$ & $62.26 \pm 15.38$ & $43.62 \pm 17.49$ \\
\hline Sex, female & $8(24.2)$ & $8(25.8)$ & $5(23.8)$ \\
\hline \multicolumn{4}{|l|}{ Occupation } \\
\hline Manual & $18(54.5)$ & $14(45.2)$ & $12(57.1)$ \\
\hline Office & $4(12.1)$ & $6(19.4)$ & $4(19.0)$ \\
\hline Unemployed & $11(33.3)$ & $11(35.4)$ & $5(23.8)$ \\
\hline \multicolumn{4}{|l|}{ Medical history } \\
\hline Diabetes & $16(48.5)$ & $27(87.1)$ & $2(9.5)$ \\
\hline Arteriopathy & $11(33.3)$ & $1(3.2)$ & $0(0)$ \\
\hline High blood pressure & $4(12.1)$ & $2(6.5)$ & $3(14.3)$ \\
\hline Other & $2(6.1)$ & $0(0)$ & $9(42.9)$ \\
\hline No prior history & $0(0)$ & $1(3.2)$ & 7 (33.3) \\
\hline \multicolumn{4}{|l|}{ Amputation type } \\
\hline Transtibial & $21(63.6)$ & $26(83.9)$ & $13(61.9)$ \\
\hline Transfemoral & $11(33.3)$ & $5(16.1)$ & $6(28.6)$ \\
\hline Transmetatarsal & $0(0)$ & $0(0)$ & $0(0)$ \\
\hline Disarticulation (Gritti's intervention) & $1(3)$ & $0(0)$ & $1(4.8)$ \\
\hline \multicolumn{4}{|l|}{ Stump condition } \\
\hline Short & $4(12.1)$ & $9(29)$ & $6(28.6)$ \\
\hline Edema & $4(12.1)$ & $5(16.1)$ & $2(9.5)$ \\
\hline Deformed & $5(15.2)$ & $7(22.6)$ & $4(19.1)$ \\
\hline Good & $20(60.6)$ & $10(32.3)$ & $9(52.3)$ \\
\hline
\end{tabular}

Values are presented as mean \pm standard deviation or number (\%).

At 12 months pain, it is noted that PW and LCI were significantly improved. The evaluation of the SIGAM score showed a significant improvement in function at that time. Regarding the QOL we observed a statistically significant improvement in MCS and PCS scores, as well as all elementary scores of the SF-36 score in the global population (Table 2). According to the amputation etiology, the improvement of PCS and MCS scores was greater in traumatic population without a statistical significance (Table 3).

It is emphasized that the physical and the mental component of the SF-36 score were negatively correlated with age ( $\mathrm{p}=0.012$ and $\mathrm{r}=-\mathbf{0 . 4 8 3}$ for PCS; $\mathrm{p}=0.032$ and $\mathrm{r}=-\mathbf{0 . 4 2 2}$ for MCS), and were less impaired in patients amputated under the knee. In addition, we found that the incidence of an amputation of traumatic origin was associated with significantly higher QOL scores than an amputation of an infectious or vascular origin (Table 4).
We found that higher physical and mental QOL scores were noticed in patients with better LCI $(\mathrm{p}<0.01$ and $\mathrm{r}=0.349$ for PCS; $\mathrm{p}<0.01$ and $\mathrm{r}=0.482$ for $\mathrm{MCS}), \mathrm{PW}(\mathrm{p}<0.01$ and $\mathrm{r}=0.413$ for PCS; $\mathrm{p}<0.01$ and $\mathrm{r}=0.317$ for MCS) and SIGAM (Table 2). Likewise, there was a negative and statistically significant correlation between the QOL and the psychological status of patients. In fact, the higher anxiety scores were associated with poor MCS ( $\mathrm{r}=-0.414)$ and PCS ( $\mathrm{r}=-0.321)$. Also, depression was associated with poor MCS $(\mathrm{r}=-0.484)$ and PCS $(\mathrm{r}=-0.467)$.

To begin with, pain was only moderately negatively correlated with Physical Functioning and Bodily Pain subdomains of the SF-36 (-0.338 and -0.469 , respectively). In this way, PW was correlated with all SF-36 subdomains, especially Social Functioning ( $\mathrm{r}=0.618$ ), Mental Health $(\mathrm{r}=0.569)$ and Vitality $(\mathrm{r}=0.564)$. It was shown that LCI was correlated with all subdomains of the SF-36 especially Vitality ( $r=0.506)$, Role Emotional $(r=0.478)$ and Physical 


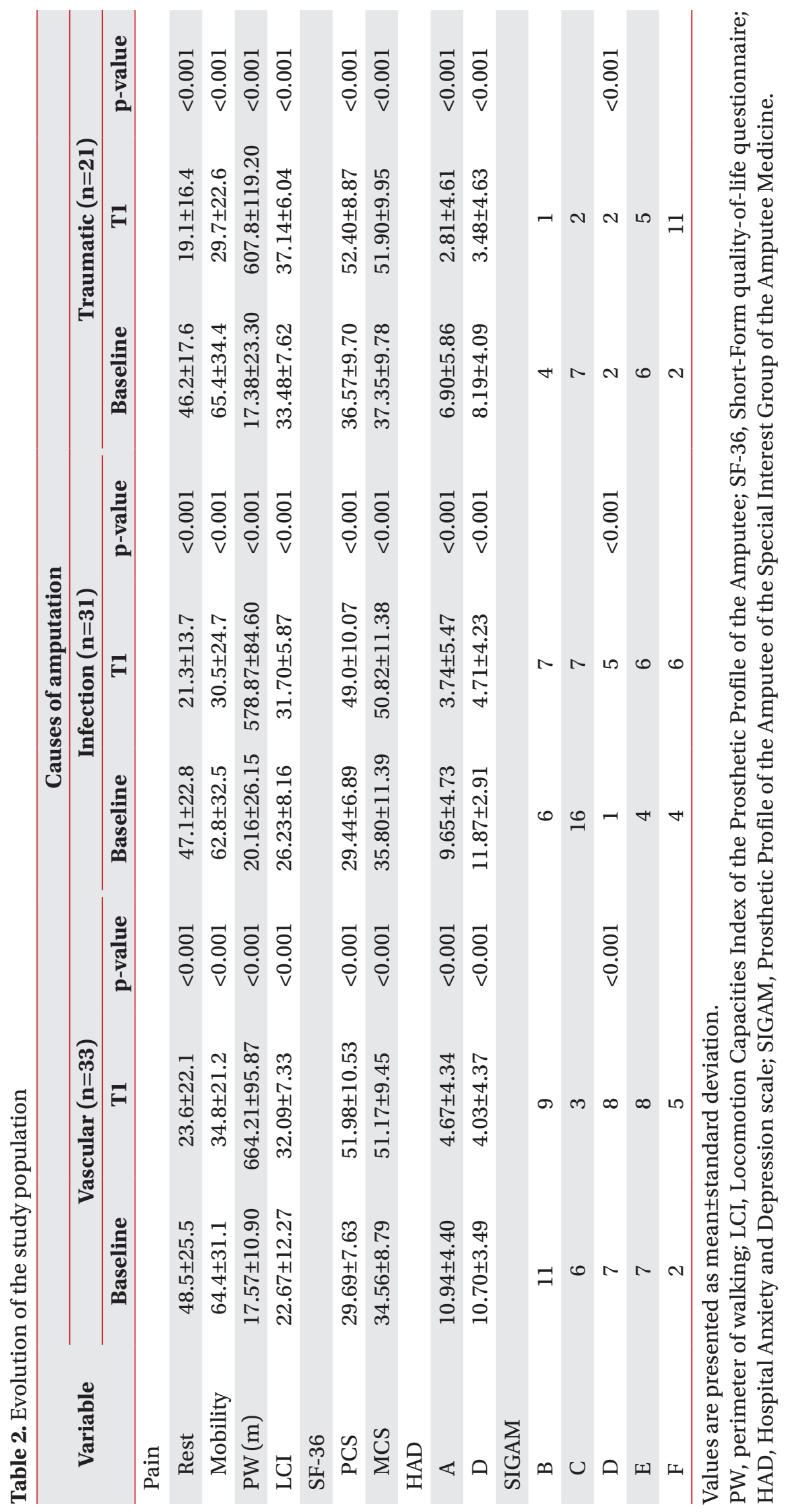


Table 3. Comparison of gain in PCS and MCS between the amputation etiology subgroups

\begin{tabular}{|lcccc}
\hline & \multicolumn{3}{c}{ Causes of amputation } & \multirow{2}{*}{ p-value } \\
\cline { 2 - 4 } & Vascular $(\mathbf{n}=\mathbf{3 3})$ & Infection $(\mathbf{n = 3 1})$ & Traumatic $(\mathbf{n = 2 1})$ & 0.8 \\
\hline Gain in PCS & $2.2 \pm 7.4$ & $3.5 \pm 7.3$ & $6.8 \pm 7.5$ & 0.3 \\
\hline Gain in MCS & $3.6 \pm 10.1$ & $4 \pm 9$ & $6.5 \pm 13.3$ & 0.3 \\
\hline
\end{tabular}

Values are presented as mean \pm standard deviation.

PCS, physical component of the SF-36 quality of life score; MCS, mental component of the SF-36 quality of life score.

Table 4. Associations between the amputation cause and quality of life

\begin{tabular}{lcccc}
\hline & & Causes of amputation & \multirow{2}{*}{ p-value } \\
\cline { 2 - 4 } & Vascular $(\mathbf{n}=\mathbf{3 3})$ & Infection $(\mathbf{n}=\mathbf{3 1})$ & Traumatic $(\mathbf{n}=\mathbf{2 1})$ & \\
\hline PCS & $31.23 \pm 10.53$ & $30.38 \pm 10.07$ & $37.26 \pm 8.87$ & 0.03 \\
MCS & $36.28 \pm 9.45$ & $35.47 \pm 11.38$ & $38.79 \pm 9.95$ & 0.012 \\
\hline
\end{tabular}

Values are presented as mean \pm standard deviation.

PCS, physical component of the SF-36 quality of life score; MCS, mental component of the SF-36 quality of life score.

Table 5. Relationship between the domains and subdomains of the SF-36

\begin{tabular}{|ccccc}
\hline & \multicolumn{3}{c}{ Well-being } & Overall evaluation of health \\
\cline { 2 - 4 } & Mental Health & Vitality & Bodily Pain & General Health \\
\hline Functional status & & & & \\
Physical Functioning & $<0.001(0.72)$ & $<0.001(0.73)$ & $<0.001(0.67)$ & $<0.001(0.72)$ \\
Social Functioning & $<0.001(0.49)$ & $<0.001(0.56)$ & $<0.001(0.6)$ & $<0.001(0.54)$ \\
Role Physical & $<0.001(0.41)$ & $<0.001(0.54)$ & $<0.001(0.5)$ & $<0.001(0.54)$ \\
Overall evaluation of health & & & & - \\
$\quad$ General Health & $<0.001(0.66)$ & $<0.001(0.64)$ & $<0.001(0.58)$ & - \\
\hline
\end{tabular}

Values are presented as p-value (r).

SF-36, Short-Form Quality-of-Life Questionnaire.

Functioning $(\mathrm{r}=0.472)$. The SIGAM was correlated with all SF-36 subdomains except the Global Health, the highest correlation was noticed with Physical Functioning $(\mathrm{r}=0.630)$ and Vitality $(\mathrm{r}=0.550)$. The HAD-A was negatively correlated with all SF-36 subdomains, the highest correlation was noticed with Mental Health ( $\mathrm{r}=-0.818$ ), Global Health ( $\mathrm{r}=-0.685)$ and Vitality ( $\mathrm{r}=-0.667)$. HAD-D was negatively correlated to all SF-36 subdomains. In this respect, the highest correlation was noticed with Mental Health ( $\mathrm{r}=-0.782)$, Global Health ( $\mathrm{r}=-0.694)$ and $\mathrm{PF}(\mathrm{r}=-0.663)$.

Among the identified functional status subdomains, Physical Functioning was especially correlated to all subdomains of the Well-being (Mental Health, Vitality, and Bodily Pain) and Overall Evaluation of Health domains. In other words, the Social Functioning and Role-Physical were moderately correlated to the Well-being and Overall Evaluation of Health (General Health) domains (Table 5).

\section{DISCUSSION}

Generally speaking, this study showed that vascular and infectious etiologies are the most frequent causes of lower limb amputation in our sample of North African patients. In its most positive context, it was shown that the QOL and functional status were altered for all patients and showed a significant improvement at followup. In this case, the QOL seems to be better with younger age and proximal amputation level. Notably, it is affected by the functional status and the etiology of the amputation. Evidently, psychological distress seems to alter the QOL of our sample of patients. The improvement of QOL in our patients was significant in the global population and in the amputation etiology subgroups.

Our findings are consistent with most authors as noted in a literature review on this topic $[10,14]$. In fact, in the 
study of Bouaziz [15], factors correlated with a better QOL were noted as including younger age, non-vascular etiologies, correct muscular and articular balance, lower HAD-A and HAD-D scores, a higher LCI score and a higher PW. According to the van der Schans et al. [9] study, the researchers found that patients who had a better PW with no phantom pain had a better QOL than the others. Furthermore, we noticed that PW was highly correlated with Social Functioning, Mental Health, and Vitality subdomains of the SF-36. The study of Abdelgadir et al. [16] evaluated the QOL of diabetic lower limb amputees in the Sudanese population, using the HRQOL quality-oflife questionnaire, and found that amputee patients with better functional status had a better QOL. On the other hand, according to Asano et al. [5], the predictive factors for a poor QOL were when the individual experienced depression, limited joint range of motion, comorbidities and older patients. In our population, depression was highly correlated to a poor Mental Health, Global Health, and Physical Functioning. In addition to these factors Sinha et al. [17] estimated that residual pain and functional restriction were also factors that were linked to a poor QOL.

Broadly speaking, it is noted that a significant segment of amputations found in our patient sample was attributed to the presence of an infectious origin. This etiology is not common in other populations where traumatic and vascular causes are dominant. This result could be explained by the fact that the majority of infection related amputations are characteristic to occur in diabetic patients. A multicenter study found that $50 \%$ of diabetic North African patients were undiagnosed [18], which is a factor that is currently putting them at a greater risk of complications in the case of a lower limb injury. The improvement of QOL in our infection subgroup was comparable to that in the vascular and traumatic subgroups.

In our study we noticed a statistically significant improvement in the QOL after acquiring the prosthesis which seems to be a determining factor in improving the QOL of amputees of the lower limb [7,8]. In fact, Abdelgadir et al. [16] found that the functional status and the PW were predictors of a better QOL. Similarly, Meatherall et al. [19] studied a Canadian sample of lower limb amputees, and found that changes in the functional status and the acquisition of prosthesis were factors influencing patient's QOL. In addition, Zidarov et al. [20] reviewed pro- spectively the QOL of a cohort of lower limb amputees, and noticed an improvement after acquiring the prosthesis, and the gain was retained over the 3-month followup. The findings of the literature are consistent with our results obtained from the study of a Tunisian sample.

There was a major limitation of our study, which was that it was a relatively small sample.

In conclusion, our study found that in a review of younger patients, the results noted a lower psychological distress, better functional status and the acquiring of prostheses which were associated with a better QOL in our sample of Tunisian lower limb amputees. Practitioners should take all of these factors into consideration during the treatment process, when planning the rehabilitation program and after the discharge of these patients, in order to ensure a better recovery of the patient, and to allow them to be reintegrated into society and to enable them to regain a better QOL. The use of multicentric prospective studies with a larger sample are suggested for better understanding the changes in QOL in lower limb amputees over time, and to assess its determinant factors.

\section{CONFLICT OF INTEREST}

No potential conflict of interest relevant to this article was reported.

\section{AUTHOR CONTRIBUTION}

Conceptualization: Migaou H, Hassine YH. Methodology: Migaou H, Jellad A, Boudokhane S. Formal analysis: Migaou H, Kalai A, Hassine YH, Jellad A. Writing - original draft: Migaou H, Kalai A, Hassine YH, Jellad A, Frih ZBS. Writing - review and editing: Kalai A, Jellad A. Approval of final manuscript: all authors.

\section{REFERENCES}

1. Biemer E. Definitions and classifications in replantation surgery. Br J Plast Surg 1980;33:164-8.

2. Ustun TB, Chatterji S, Bickenbach J, Kostanjsek N, Schneider M. The International Classification of Functioning, Disability and Health: a new tool for understanding disability and health. Disabil Rehabil 2003;25:565-71. 
3. Geertzen JH. Moving beyond disability. Prosthet Orthot Int 2008;32:276-81.

4. Desmond DM, MacLachlan M. Coping strategies as predictors of psychosocial adaptation in a sample of elderly veterans with acquired lower limb amputations. Soc Sci Med 2006;62:208-16.

5. Streppel KR, de Vries J, van Harten WH. Functional status and prosthesis use in amputees, measured with the Prosthetic Profile of the Amputee (PPA) and the short version of the Sickness Impact Profile (SIP68). Int J Rehabil Res 2001;24:251-6.

6. Ackerley SJ, Gordon HJ, Elston AF, Crawford LM, McPherson KM. Assessment of quality of life and participation within an outpatient rehabilitation setting. Disabil Rehabil 2009;31:906-13.

7. Schoppen T, Boonstra A, Groothoff JW, Vries DJ, Goeken NH, Eisma WH. Epidemiologic characteristics and quality of life of lower limb amputee patients in adulthood in the Netherlands. In: Schoppen T, editor. Functional outcome after a lower limb amputation. Groningen: Northern Centre for Healthcare Research; 2002. p. 59-74.

8. Asano M, Rushton P, Miller WC, Deathe BA. Predictors of quality of life among individuals who have a lower limb amputation. Prosthet Orthot Int 2008;32:231-43.

9. van der Schans CP, Geertzen JH, Schoppen T, Dijkstra PU. Phantom pain and health-related quality of life in lower limb amputees. J Pain Symptom Manage 2002;24:429-36.

10. Demet K, Martinet N, Guillemin F, Paysant J, Andre JM. Health related quality of life and related factors in 539 persons with amputation of upper and lower limb. Disabil Rehabil 2003;25:480-6.

11. Ware JE Jr, Sherbourne CD. The MOS 36-item shortform health survey (SF-36). I. Conceptual framework and item selection. Med Care 1992;30:473-83.

12. Gauthier-Gagnon C, Grise MC. Prosthetic profile of the amputee questionnaire: validity and reliability. Arch Phys Med Rehabil 1994;75:1309-14.

13. Zigmond AS, Snaith RP. The hospital anxiety and depression scale. Acta Psychiatr Scand 1983;67:361-70.

14. Sinha R, van den Heuvel WJ, Arokiasamy P. Factors affecting quality of life in lower limb amputees. Prosthet Orthot Int 2011;35:90-6.

15. Bouaziz MA. Epidemiological and clinical characteristics, functional and quality of life of patients with major lower limb amputees in central Tunisia [master's thesis]. Sousse, Tunisia; Faculty of Medicine Ibn El Jazzar: 2014.

16. Abdelgadir M, Shebeika W, Eltom M, Berne C, Wikblad K. Health related quality of life and sense of coherence in Sudanese diabetic subjects with lower limb amputation. Tohoku J Exp Med 2009;217:45-50.

17. Sinha R, van den Heuvel WJ, Arokiasamy P, van Dijk JP. Influence of adjustments to amputation and artificial limb on quality of life in patients following lower limb amputation. Int J Rehabil Res 2014;37:74-9.

18. Ben Romdhane H, Ben Ali S, Aissi W, Traissac P, Aounallah-Skhiri H, Bougatef S, et al. Prevalence of diabetes in Northern African countries: the case of Tunisia. BMC Public Health 2014;14:86.

19. Meatherall BL, Garrett MR, Kaufert J, Martin BD, Fricke MW, Arneja AS, et al. Disability and quality of life in Canadian aboriginal and non-aboriginal diabetic lower-extremity amputees. Arch Phys Med Rehabil 2005;86:1594-602.

20. Zidarov D, Swaine B, Gauthier-Gagnon C. Life habits and prosthetic profile of persons with lower-limb amputation during rehabilitation and at 3-month followup. Arch Phys Med Rehabil 2009;90:1953-9. 